\title{
O Papel do Gerente num Contexto de Mudança Baseada no Uso da Tecnologia CRM
}

\author{
Raquel Oliveira Xavier \\ Jairo Simião Dornelas
}

\section{Resumo}

Este trabalho destina-se a investigar o papel do gerente no que concerne ao trato com o cliente, em face da utilização de um sistema de gerência do relacionamento com o cliente (CRM), uma vez que a gerência é apontada como principal agente numa mudança organizacional baseada em tecnologia. A pesquisa se deu por meio de um estudo de caso em profundidade numa empresa que é, ao mesmo tempo, usuária e fornecedora de tecnologia e que está implantando um sistema de CRM, cujos principais usuários são os gerentes regionais. Foram realizadas entrevistas em abrangência nacional, com perguntas elaboradas a partir da revisão bibliográfica, nas áreas de mudança organizacional, marketing de relacionamento, tecnologia da informação e gestão do relacionamento com o cliente, utilizando a técnica de análise de conteúdo. Constataram-se resultados significativos sobre a potencialidade de uso do sistema, a qual requer mudanças nos processos e inclui uma postura gerencial mais proativa em relação ao contato e atendimento do cliente, possibilitando gerenciamento mais efetivo e melhor planejamento das atividades.

Palavras-chaves: tecnologia da informação; gerenciamento relacionamento com o cliente (CRM); mudança organizacional - gerência.

\begin{abstract}
This work is intended to investigate the manager role, due to the utilization of a Customer Relationship Management System (CRM), that is regarded as the main agent in a technologybased organizational change. The research took place during a deep case study of a company that is, at the same time, user and supplier of technology, and is implementing a CRM system whose main users are regional managers. To produce the research, interviews with the managers were realized, with questions elaborated from the literature revision, in the areas of organizational change, relationship marketing, information technology, and customer relationship management. The content analysis technique was utilized for the collected data examination. Significant results were established about the potentiality of the system use, which requires processes changes and involve a more pro-active managerial posture regarding customer service and contact, making possible a more effective management and a better planning of activities.
\end{abstract}

Key words: information technology; customer relationship management (CRM); organizational change-management. 


\section{INTRODUÇÃO}

Neste estudo, pretende-se abordar as mudanças percebidas e geradas em face da utilização da tecnologia de CRM por gerentes de uma empresa de informática. O objetivo geral da pesquisa é o de avaliar a mudança na postura dos gerentes regionais de uma empresa de tecnologia de informática, a partir da implantação e utilização de um sistema de Gestão de Relacionamento com o Cliente (CRM), considerando a atuação do gerente junto ao cliente. Pretende-se, ainda, identificar mudanças nos processos de trabalho para a atividade gerencial, provenientes do uso da tecnologia, identificar novos perfis de atuação para os gerentes, em função do uso da tecnologia de CRM, avaliar a melhoria na relação com o cliente por meio do uso das informações disponibilizadas pelo sistema e identificar, para a empresa, vantagens associadas ao uso do CRM.

Sabe-se que a tecnologia é fator vital para as organizações na obtenção de competitividade, num mercado em constante mudança, com um consumidor cada vez mais exigente e orientado para informações e conhecimentos. Sabe-se, também, que a idéia de criar um relacionamento com o cliente ao longo do tempo não é resultado deste desenvolvimento tecnológico. Na verdade, a tecnologia apenas tem mudado o método de estabelecer esse relacionamento.

Um sistema de gerenciamento do relacionamento com o cliente (Customer Relationship Management - CRM) é uma estratégia que envolve tecnologia de informação, processos de negócios e atitude empresarial que somam forças para gerar diferencial competitivo por meio do relacionamento com os clientes (Lopes, 2001). Em um CRM, focalizam-se a forma de se relacionar com os clientes e as adaptações internas decorrentes disso. A implementação de software de gestão e de manipulação de informação não prevê apenas novos dados ou novas filosofias de gerenciamento, mas maneiras mais eficientes de se efetivar o relacionamento.

A atuação do gerente é importante neste contexto, uma vez que ele estabelece contato direto com o cliente e pode perceber direcionamentos e atender às suas necessidades. $\mathrm{O}$ gerente deve ter visão estratégica que possibilite abertura a mudanças, câmbio de planos táticos para aproveitar oportunidades e atenção ao mercado, centrado nas necessidades dos clientes e orientado a resultados (Manzione Jr., 2001).

As mudanças relacionadas à implantação de um sistema de CRM caracterizamse por pontos de fragmentação (dificuldades encontradas) e pontos de coesão (facilitadores do processo), conforme esquema apresentado no Quadro 1 a seguir. 


\section{Quadro 1: CRM e a Transformação dos Processos de Negócios}

\begin{tabular}{|l|l|l|}
\hline \multicolumn{2}{|c|}{ CRM E A TRANSFORMAÇÃO DOS PROCESSOS DE NEGÓCIOS } \\
\hline \hline MUDANÇAS & \multicolumn{1}{|c|}{ FRAGMENTAÇãO } & \multicolumn{1}{c|}{ COESÃO } \\
\hline ORGANIZACIONAIS & $\begin{array}{l}\text { Foco no financeiro e } \\
\text { industrial } \\
\text { Foco no funcional ou } \\
\text { departamental }\end{array}$ & $\begin{array}{l}\text { Foco no cliente } \\
\text { Satisfação do cliente } \\
\text { Integração entre o cliente e a } \\
\text { empresa }\end{array}$ \\
\hline TECNOLÓGICAS & $\begin{array}{l}\text { Unidades sem } \\
\text { integração }\end{array}$ & $\begin{array}{l}\text { Integração do front office e do } \\
\text { back office } \\
\text { Sincronismo com os } \\
\text { consumidores }\end{array}$ \\
\hline COMPORTAMENTAIS & $\begin{array}{l}\text { Foco no } \\
\text { desenvolvimento } \\
\text { individual }\end{array}$ & $\bullet \begin{array}{l}\text { Foco na equipe } \\
\text { Colaboração voluntária }\end{array}$ \\
\hline
\end{tabular}

Fonte: adaptado de Chein e Cabrera, 2000.

As mudanças organizacionais no direcionamento de foco no cliente envolvem todas as áreas da empresa, não só a área de marketing e vendas. Uma empresa voltada para o cliente procura atingir os seus objetivos de busca da satisfação do cliente e de manutenção dos lucros, por meio de um sistema integrado de informações que facilite a interação das diversas áreas e que reforce suas regras e procedimentos, visando à consistência, padronização e controle (Chein \& Cabrera, 2000).

O objetivo do CRM, neste contexto, é fornecer tais elementos informacionais, funcionais e de projeção, que possibilitem ao gerente um comportamento proativo e adequado a explorar as potencialidades do cliente. $\mathrm{O}$ que se pretende avaliar, então, é se este comportamento gera nova postura e se esta pode ser creditável à exploração das potencialidades do CRM.

\section{Referencial Conceitual}

O embasamento teórico-conceitual do presente estudo aborda os tópicos de mudanças organizacionais, tecnologia da informação, marketing e gestão do relacionamento com o cliente, que é apresentado como a combinação da tecnologia da informação (TI) e do marketing de relacionamento.

A Figura 1 apresenta a visualização do esquema que compreende as implicações das mudanças organizacionais no ambiente gerencial e mostra a importância do sistema de gerenciamento do relacionamento com clientes (CRM), como 
resultado do marketing de relacionamento e da tecnologia da informação numa organização voltada para o cliente.

Figura 1: Roteiro das Referências Conceituais da Pesquisa

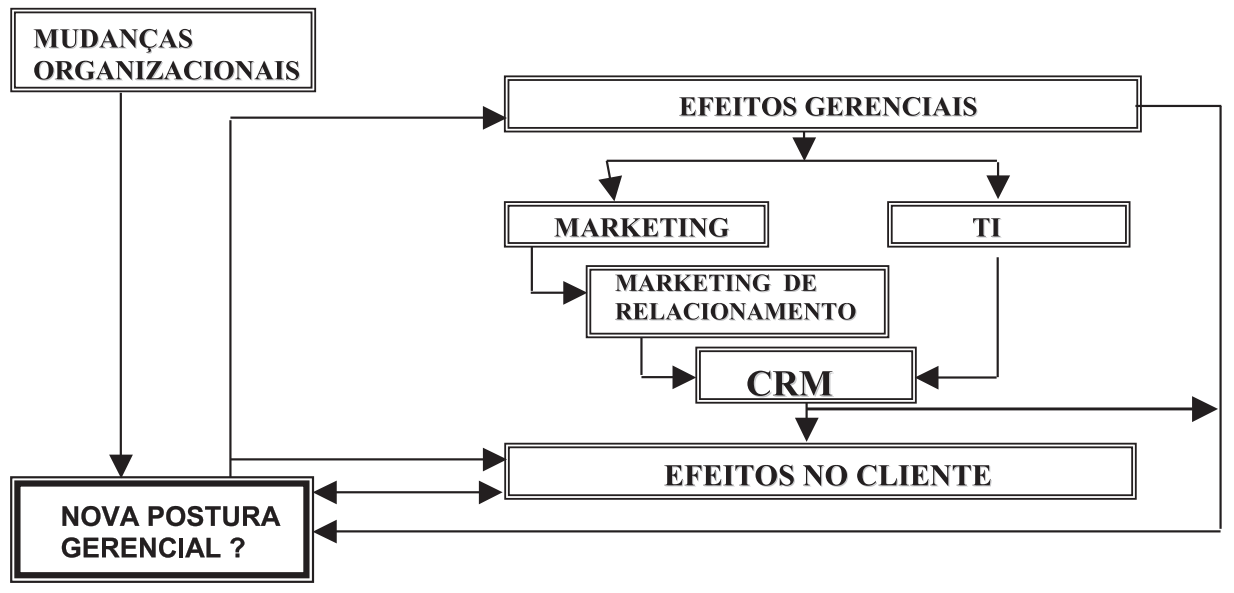

\section{Mudança Organizacional}

O processo de mudança organizacional começa com o surgimento de forças que criam a necessidade de mudança em alguma parte da organização, e podem ser exógenas ou endógenas à organização. A tecnologia, mudança em valores da sociedade, novas oportunidades e limitações do ambiente econômico, político e social são forças externas que criam a necessidade de mudança organizacional interna (Shirley, 1976).

A rapidez com que as mudanças no ambiente externo afetam as empresas requer o desenvolvimento de eficientes estratégias de aquisição de informações internas e externas (Petrini \& Pozzebon, 2000).

Para Machado-da-Silva, Fonseca e Fernandes (1999) as organizações sentemse pressionadas a promover mudanças estratégicas em face do ambiente crescentemente competitivo; mas, em grande parte destes processos de mudança, a transformação organizacional pode ser administrada.

A mudança é um programa intensivo de ações que deve ser precedido de um planejamento que defende a transformação proposta e demonstra sua necessidade e vantagens. Preparar a organização para o que virá é justamente construir o contexto da mudança. A figura do agente de mudança surge, então, como líder ou guia da nova situação organizacional, interagindo e alimentando novos valores, 
atitudes e comportamentos por meio da identificação e internalização das ações inerentes ao processo de mudança.

\section{O Papel do Gerente como Agente de Mudança}

Tapscott e Caston (1995) afirmam que as mudanças fundamentais que estão ocorrendo no atual ambiente empresarial, associadas à ascensão do novo paradigma da tecnologia, estão começando a apresentar grande desafio para as organizações. As principais dificuldades não se encontram na área tecnológica, mas nas estruturas organizacionais. O desafio é de mudança no enfoque gerencial. A mudança exige uma visão diferente dos líderes estabelecidos, que necessitam compreender a transição que têm diante de si, para alcançar os resultados exigidos pelo ambiente empresarial novo e competitivo.

Uma das mudanças mais significativas que Homburg, Workman e Jensen (2000) encontraram em sua pesquisa relativa à estrutura organizacional, orientada ao cliente, foi um aumento da ênfase no gerente de conta e o estabelecimento de gerentes por segmento de clientes dentro da organização de vendas. $\mathrm{O}$ gerente de conta, no contexto da referida pesquisa, é definido como a designação de uma pessoa especial responsável pelo desempenho das atividades dirigidas para os clientes mais importantes da organização. Muitas empresas, no intuito de desenvolver relacionamentos mais próximos aos clientes, vislumbraram, nos gerentes de conta, maneira de atingir seu objetivo.

O estilo decisório destes gerentes, aquilo que lhes dá mais categoria ou visibilidade para o cenário externo, é justamente a capacidade cognitiva, o modo de pensar (Dornelas, 2002). Neste sentido, Bateman e Crant (1993) exploram a proatividade no comportamento organizacional, identificando diferenças entre pessoas e em que grau suas ações influenciam o ambiente, quanto à iniciativa, identificação de oportunidades e tomada de decisão. Esses autores concluem que a disposição para a proatividade é uma tendência para iniciar e manter ações que alteram o ambiente.

\section{Marketing}

O marketing sempre foi alvo de discussões quanto à sua conceituação. Uma definição bem aceita é a apresentada pela American Marketing Association, em 1985, citada por Casotti (1995, p. 12): “marketing é o processo de planejar e executar a concepção, o preço, a promoção e distribuição de idéias, produtos e serviços para criar trocas que satisfaçam os objetivos de indivíduos e organizações". 
No entanto muitos autores têm argumentado que, além da sua característica funcional, o marketing é uma filosofia organizacional e sua evolução se tem dado para atender às necessidades de atuação das organizações em face da demanda dos clientes e da conjuntura do mercado (Carey, 1989; Mckenna, 1998; Rapp \& Collins, 1991). Uma síntese dessa evolução foi apresentada por Bretzke (2000), em termos de uso do marketing. Cada uma das eras descritas: era do marketing de massa, era da segmentação, era do nicho, era do cliente e era do tempo real, trouxe grandes mudanças organizacionais e maneiras de atuação no mercado.

Carey (1989) salienta que o desafio do marketing é descodificar o modo de pensar, de compreender e lidar com a realidade, oferecendo as informações necessárias para que os executivos possam tomar decisões, com base no conhecimento do ponto de vista do cliente. O diálogo e a construção de relacionamentos estáveis e duradouros com os clientes surgem como resposta ao desafio imposto ao marketing pelas mudanças no ambiente competitivo e no comportamento do consumidor.

\section{Marketing de Relacionamento}

Para McKenna (1998), o marketing de relacionamento é a resposta para as empresas enfrentarem o desafio das mudanças, pois se baseia na experiência e exige o domínio do conhecimento sobre a tecnologia inerente a sua atividade, seus concorrentes, seus clientes; novas tecnologias podem modificar o ambiente competitivo e sua própria organização: capacidades, recursos, planos e formas de negociar. Sob essa ótica e impulsionado por forte aporte de tecnologia, o marketing passou a receber a transferência de atividades, funções e poder que eram, tradicionalmente, de outras áreas.

De acordo com Dwyer, Schurr e Oh (1987), entender o marketing de relacionamento requer distinguir entre uma transação discreta, que tem um começo distinto, curta duração e finalização precisa, por desempenho e mudança relacional que estabelecem concordância prévia, de maior duração e refletem um processo contínuo.

Applegate, Holsapple, Kalakota, Radermacher e Whinston (1996) afirmam que o relacionamento com o cliente vai além da compra e venda de produtos, incluindo diversas atividades e esforços de pré-venda e pós-venda, com novos enfoques para pesquisa de mercado, condução qualificada de vendas, distribuição de produtos, suporte a clientes, relações públicas, operações de negócios, distribuição de conhecimento e transações financeiras. Essas atividades afetam o planejamento estratégico e o desempenho da empresa. 


\section{Tecnologia da Informação}

Os investimentos em tecnologia da informação têm aumentado significativamente, em especial porque se percebe seu papel estratégico na empresa, à medida que a capacita e propõe mudanças na reformulação dos processos internos e dos relacionamentos externos.

O alinhamento do planejamento estratégico dos negócios com o de tecnologia da informação (TI) traz congruência à gestão estratégica dos negócios e é percebido como poderoso instrumento, capaz de alavancar grandes mudanças na organização (Morton, 1991; Meirelles, 1994; Venkatraman, 1994). Entre estas mudanças incluem-se o aperfeiçoamento do serviço ao cliente, a qualidade dos produtos, melhor tempo de resposta e maior personalização de atendimento (Brynjolfsson \& Hitt, 1996).

Torkzadeh e Doll (1999) avaliaram os efeitos dos investimentos em TI por meio da satisfação do usuário de um sistema de informação e desenvolveram um instrumento que possibilita o estudo do impacto da TI sobre o indivíduo nas dimensões de produtividade, inovação das tarefas, satisfação do usuário e controle gerencial.

\section{Gerenciamento do Relacionamento com o Cliente (CRM)}

O CRM é a combinação da filosofia do marketing de relacionamento, que mostra a importância de atrair e reter clientes, cultivando um relacionamento estável e duradouro, com a infra-estrutura da tecnologia da informação, que provê recursos integrados de informática e telecomunicações, provocando impacto na gestão da empresa quanto aos comportamentos de recursos humanos e processos.

Para Swift (2001), o aspecto mais significativo do processo de CRM é o aprendizado contínuo e a criação do conhecimento a respeito dos clientes, a fim de atingir objetivos e obter mais lucratividade em longo prazo.

Para atingir tais benefícios, Davis e Joyner (2000) lembram que a empresa deve estar preparada para um engajamento e interação proativos com o cliente. Isso envolve muita colaboração em toda a organização e a tecnologia é vital para tal fim.

Contudo a tecnologia de CRM, como mera ferramenta, sem a definição e o planejamento do modelo de relacionamento e sem o redesenho dos processos de atendimento ao cliente, será apenas um projeto de informatização de call center, como função de apoio, sem implementar o conceito de cliente-interativo, com respostas em tempo real (Bretzke, 2000). 
O foco nos relacionamentos e satisfação dos clientes como ponto central para a estratégia organizacional e a filosofia de gerenciamento requer mudança na cultura corporativa (Anton, 1996) e, talvez, nova postura gerencial.

\section{Metodologia}

Uma vez que o objetivo dessa pesquisa foi aumentar o conhecimento e a compreensão da postura gerencial, percebida em face das mudanças tecnológicas, a pesquisa qualitativa de caráter exploratório é a mais adequada, porque enfatiza a exploração do assunto a ser estudado num universo de verificação e análise do fenômeno, possibilitando maior conhecimento sobre o tema, envolvendo a obtenção de dados descritivos sobre pessoas, lugares e processos interativos, por contato direto do pesquisador com a situação desejada, no intuito de compreender os fenômenos segundo a perspectiva dos participantes da situação em estudo (Churchill, 1999; Godoy, 1995; Marshall \& Rossman, 1994).

A estratégia de pesquisa adotada para o presente estudo foi a do estudo de caso e optou-se pelo estudo de caso único com caso selecionado por conveniência. Para isso, foram tomadas providências para que fosse feita uma investigação criteriosa e cuidadosa do cenário, minimizando as chances de equívocos e maximizando as evidências do estudo para possibilitar o aprofundamento que a estratégia oferece (Laville \& Dione, 1999; Miles \& Huberman, 1994; Yin, 2001). Buscando aumentar a confiabilidade do estudo de caso, foi desenvolvido um protocolo que contém os procedimentos e regras gerais relativas à investigação e à condução do estudo (Yin, 2001).

\section{Delineamento da Pesquisa}

O trabalho ocorreu numa empresa de informática que é, simultaneamente, fornecedora e usuária de tecnologia da informação. A empresa está implantando um sistema de gerenciamento do relacionamento com o cliente e tem como usuários principais os gerentes regionais de vendas. Tal escolha foi lastreada pela franquia de acesso do pesquisador à empresa a ser estudada e ao âmbito de atuação dela: a empresa tem abrangência nacional e há forte relacionamento do gerente regional com o cliente, o que possibilita observar possíveis mudanças gerenciais.

A pesquisa foi realizada junto aos Gerentes Regionais de Vendas (GRV) da empresa, os Gerentes Executivos de Vendas (GEV) e gerentes de informática de empresas clientes em diversos Estados. 
Sendo o desenho de pesquisa uma forma esquemática que auxilia o pesquisador a imprimir ordem lógica ao trabalho (Marconi \& Lakatos, 1990), para o presente estudo foi desenvolvido o desenho de pesquisa a seguir.

\section{Figura 2: Desenho de Pesquisa}

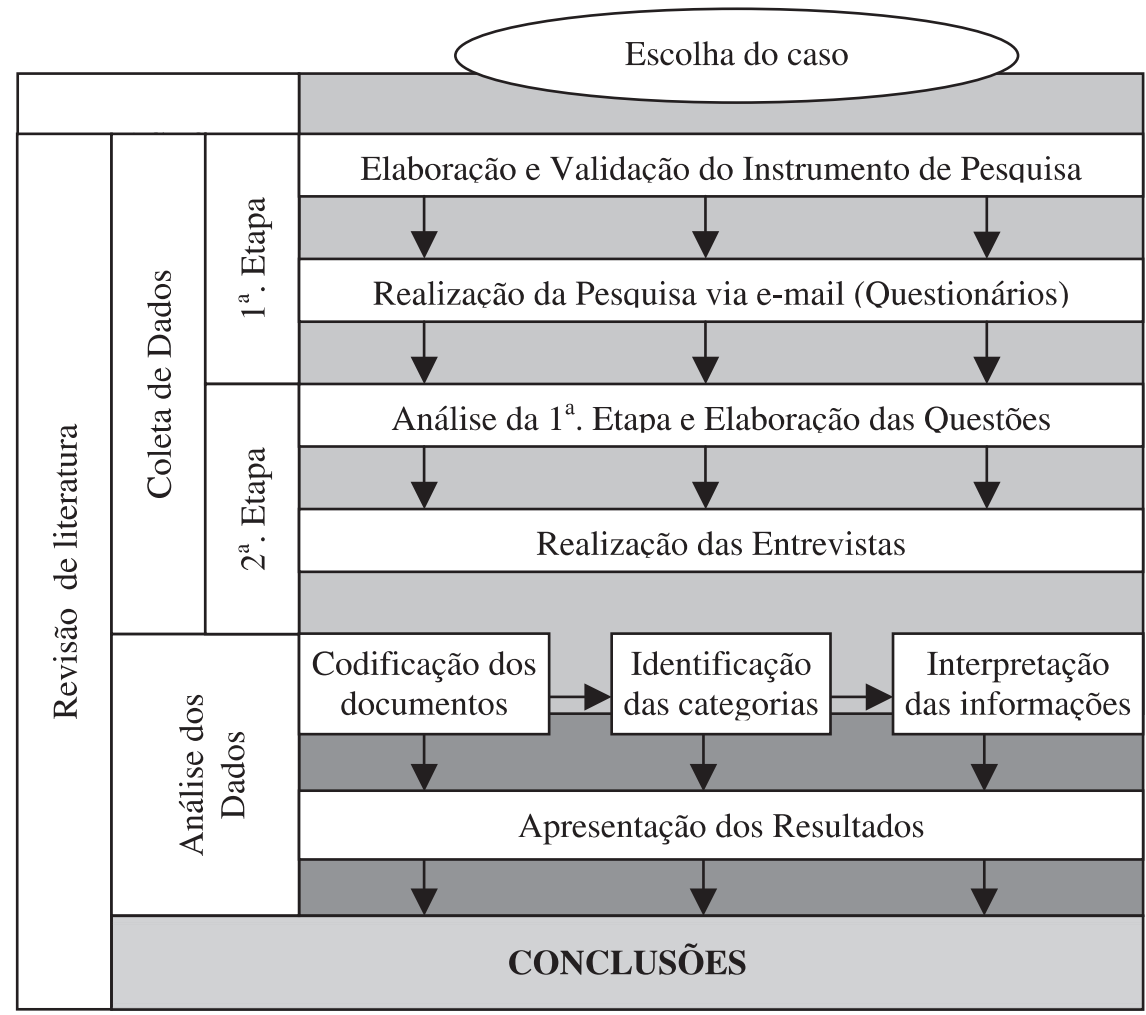

\section{Coleta dos Dados}

A coleta de dados se deu em duas etapas. Na primeira fez-se uso de questionário com perguntas abertas, aplicado à maioria dos gerentes regionais de vendas. Essa etapa foi precedida por um pré-teste com um grupo de gerentes de tecnologia de empresas locais que utilizavam um sistema de CRM ou que tivessem intenção de fazê-lo e também com um grupo de mestrandos. Tal atividade possibilitou a validação de face das questões abordadas quanto à compreensão, seqüência, forma, vocabulário e adequação aos objetivos de mensuração a serem atingidos, tanto do ponto de vista gerencial quanto do acadêmico. $\mathrm{O}$ instrumento de pesquisa ficou estruturado com 11 variáveis e 23 perguntas abertas, mais a pergunta síntese. 
$\mathrm{Na}$ segunda etapa foram realizadas entrevistas de confirmação com três Gerentes Regionais de Vendas (GRV), os dois Gerentes Executivos de Vendas (GEV) e cinco clientes. A escolha dos entrevistados foi por conveniência, considerando a proximidade, a oportunidade e a disponibilidade dos entrevistados.

\section{Triangulação}

O conteúdo das questões das entrevistas com os GRVs e com os GEVs foi similar ao dos questionários; mas as perguntas já incorporaram alguns dos resultados obtidos na análise dos questionários da primeira etapa. Tal procedimento possibilitou a triangulação dos dados provenientes de diferentes fontes de evidência.

A triangulação proposta por Stake (1994) e Miles e Huberman (1994) procura determinar se há pontos de convergência entre as fontes de informação com a finalidade de atender ao pressuposto da validade interna. Yin (2001) define triangulação como fundamento lógico de utilização de várias fontes de evidência.

As perguntas pertinentes à entrevista com clientes confrontaram expectativa $\mathrm{e}$ percepção sobre qualidade de atendimento, produtos e serviços, melhoria da atenção, satisfação, proximidade e variedade de contato, periodicidade de visitas, disponibilidade, entre outros.

Após cada entrevista, foi elaborado um resumo com as principais considerações sobre as condições da entrevista e sobre o comportamento do entrevistado. Esse resumo é parte do diário de campo que também serviu de elemento para triangulação.

\section{Análise dos Dados}

A análise de conteúdo foi a técnica mais adequada para o estudo proposto porque é utilizada para fazer inferências sobre comunicação, tanto do emissor, quanto do receptor e também da própria mensagem, identificando intenções e características, descrevendo respostas a atitudes e comportamentos dos agentes da comunicação e descrevendo tendências no conteúdo da mensagem (Krippendorf, 1980; Stone \& Kirsch, 1996; Weber, 1990).

Bardin (1977) propõe as seguintes fases como componentes do processo de análise de conteúdo: pré-análise, codificação, categorização, análise e interpretação, apresentadas na Figura 3. 


\section{Figura 3: Fases do Processo de Análise de Conteúdo}

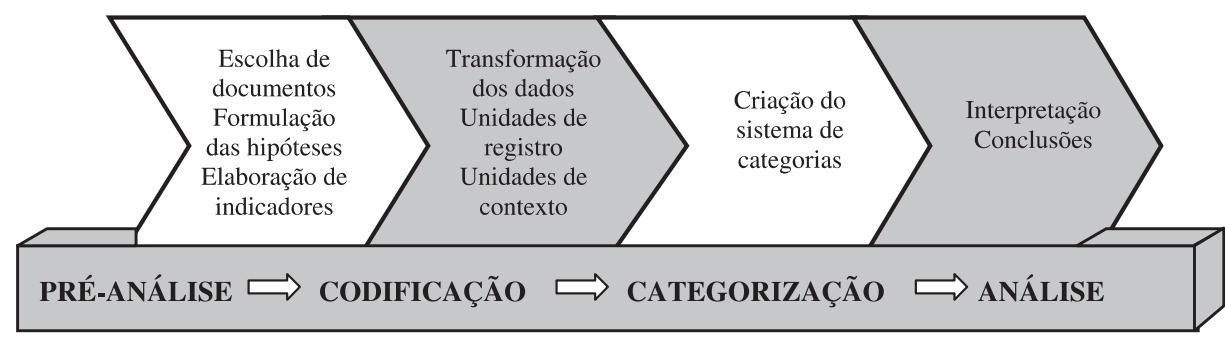

Fonte: Bardin, 1977.

Foi feita a análise interpretativa dos dados pelo método de análise de conteúdo que, com base nas informações dos entrevistados, possibilitou a categorização e o agrupamento dos dados, definindo temas comuns às respostas e comparandoos com os temas propostos.

A análise de conteúdo foi realizada em dois momentos distintos. Num primeiro momento, na pré-análise, os documentos utilizados foram os questionários da primeira etapa da pesquisa, e os objetivos propostos serviram de base para a verificação e elaboração das questões. A codificação se deu pela presença de palavras e temas e a categorização foi, fundamentalmente, baseada na revisão teórica e conceitual. A análise e interpretação forneceram conclusões que serviram de subsídio para a elaboração do roteiro da entrevista.

A análise de conteúdo também foi aplicada à análise das entrevistas. A diferença se deu na fase da pré-análise, pela inclusão de observações e constatações decorrentes das respostas dos questionários, e na fase da categorização que utilizou também categorias previamente formuladas.

Para reforçar a análise de conteúdo foi realizada também a análise de correspondências para avaliação e comparação entre variáveis e suas categorias. Tal técnica é recurso de destaque na análise multivariada de um conjunto de dados estritamente categóricos, graças à sua flexibilidade e facilidade de interpretação (Hair, Anderson, Tatham, \& Black, 1994).

\section{AnÁlise dos Resultados}

Os resultados apresentados referem-se à análise das variáveis demográficas, das onze variáveis do estudo e da pergunta síntese. Os gráficos e tabelas apresentados foram formulados a partir do uso do sistema Sphin $x^{\circledR}$. 


\section{Análise Descritiva das Variáveis Demográficas}

O perfil do público-alvo do estudo (gerentes) foi analisado quanto à idade, escolaridade, formação acadêmica e tempo de empresa. $\mathrm{O}$ intervalo de idade predominante é na faixa de 41 a 50 anos e a maioria dos respondentes contabiliza entre 5 e 15 anos de tempo na empresa. Dentre os pesquisados, 17 têm nível universitário e 7 são pós-graduados, havendo predominância de formação acadêmica em Administração e Informática.

\section{Análise Univariada}

A tecnologia de CRM disponibilizada dá sustentação ao novo modelo de empresa previsto por Tapscott e Caston (1995), distribuindo informação e poder de decisão aos gerentes. Nessa estrutura, o gerente de conta é uma pessoa responsável pelo desempenho das atividades dirigidas para os clientes (Homburg, Workman, $\&$ Jensen, 2000). Os resultados da pesquisa mostraram que os principais papéis do gerente foram o contato e o atendimento ao cliente, conferindo-lhe postura de agente de mudança com responsabilidade da melhoria dos negócios.

O gerente desenvolve diferentes habilidades, atitudes, expectativas e percepções, decorrentes da mudança. Não obstante, no estudo são identificados, também, níveis de resistência à utilização do CRM. Estas resistências são justificadas pelos itens: avaliação da tecnologia, gerenciamento da mudança e implantação deficiente, conforme Tabela 1.

Curiosamente, os gerentes executivos consideraram que há resistência ao uso do CRM, enquanto os gerentes regionais afirmaram não serem resistentes; porém, em virtude das dificuldades de infra-estrutura e capacitação adequada, não utilizam o sistema como deveriam. Isto se torna inegavelmente um entrave à utilização plena do CRM.

Tabela 1: Nível de Resistência dos Gerentes

\begin{tabular}{c|c}
\hline \hline Nível de Resistência & $\begin{array}{c}\text { No. } \\
\text { Citações }\end{array}$ \\
\hline Sem resistência & 9 \\
\hline Resistência natural & 7 \\
\hline Aberto ao novo & 5 \\
\hline Avaliação da tecnologia & 4 \\
\hline Melhor gerenciamento da mudança & 3 \\
\hline Implantação deficiente & 2 \\
\hline \hline
\end{tabular}


Com efeito, Manzione Jr. (2001) afirma que as atitudes dos usuários refletem o seu nível de comprometimento com a implantação do CRM, levando-os a ser mais resistentes quando não percebem vantagem coletiva ou individual no uso do sistema. Portanto pode-se atribuir certa resistência à utilização do sistema, não à falta de comprometimento com os resultados, mas às dificuldades mencionadas na implantação e comunicação.

As variáveis produtividade e inovação não foram muito enfatizadas, embora os resultados mostrem a percepção de tempo gasto antes e depois do uso do CRM e a possibilidade de idéias inovadoras quanto a tarefas e processos. $\mathrm{O}$ crescimento da produtividade também inclui o aperfeiçoamento do serviço ao cliente, a variedade e qualidade dos produtos, o melhor tempo de resposta e a maior personalização de produtos e serviços.

Sob esta ótica, é possível concluir pelos resultados apresentados, que a TI possibilitou apoio às atividades gerenciais e à tomada de decisão, que apóiam o gerente e a empresa no seu contato e no atendimento das necessidades dos clientes com maior rapidez. Mas, também por esta ótica, evidencia-se a problemática da falta de infra-estrutura de comunicação como dificultadora da melhoria de produtividade e inovação. Ainda sobre inovação, pode-se concluir que é necessária uma readequação dos processos com conseqüente redesenho do perfil gerencial na sua execução.

As dificuldades encontradas, Tabela 2, referem-se, em grande parte, a deficiências na estratégia de implantação, como alertadas por Bretzke (2000). Tais dificuldades interferem no uso do CRM, dificultando a inovação dos processos e do perfil gerencial. Mediante os benefícios e dificuldades advindos do uso do CRM, pode-se avaliar a satisfação do usuário do sistema, conforme proposto por Maçada e Borenstein (2000).

Tabela 2: Dificuldades Encontradas na Utilização do CRM

\begin{tabular}{c|r}
\hline \hline Dificuldades no CRM & $\begin{array}{c}\text { No. } \\
\text { Citações }\end{array}$ \\
\hline Deficiência de entrada de dados & 6 \\
\hline Tempo de resposta & 4 \\
\hline Falta de treinamento & 4 \\
\hline Implantação inadequada e incompleta & 3 \\
\hline Não envolvimento de todas as áreas & 2 \\
\hline \hline
\end{tabular}


Também foram evidenciados benefícios trazidos pela utilização da ferramenta para o gerenciamento do relacionamento com o cliente nos níveis operacional, colaborativo e analítico, como apregoado na literatura (Poser, 2001) e exibido na Tabela 3, em função dos resultados obtidos.

\section{Tabela 3: Benefícios da Utilização do CRM}

\begin{tabular}{c|r}
\hline \hline Benefícios do CRM & \multicolumn{1}{|c}{$\begin{array}{c}\text { No. } \\
\text { Citações }\end{array}$} \\
\hline Gerenciamento do relacionamento com o cliente & 13 \\
\hline Informação consolidada e centralizada & 9 \\
\hline Controle de contas & 5 \\
\hline Facilidade administrativa & 5 \\
\hline Identificação de necessidades & 4 \\
\hline Planejamento do trabalho & 3 \\
\hline Registro histórico & 2 \\
\hline \hline
\end{tabular}

O controle gerencial, proporcionado pela TI por meio de um sistema de CRM e confirmado pelos resultados da pesquisa, permite acompanhar todo o ciclo do relacionamento com o cliente, apontado por Anton (1996) como uma das principais características que devem estar presentes neste tipo de solução. Evidências constatadas para o controle no âmbito desta pesquisa constam da Tabela 4.

\section{Tabela 4: Facilidades para o Controle Gerencial no Processo de Trabalho}

\begin{tabular}{c|r}
\hline \hline Controle Gerencial & $\begin{array}{c}\text { No. } \\
\text { Citações }\end{array}$ \\
\hline Informações dos clientes & 11 \\
\hline Registros dos contatos & 11 \\
\hline Acompanhamento do relacionamento & 7 \\
\hline Informações sobre produtos & 5 \\
\hline Melhoria do processo de trabalho & 5 \\
\hline Integração de diversas áreas da empresa & 4 \\
\hline Registro de contatos & 4 \\
\hline Regras de negócio da empresa & 3 \\
\hline Ações rápidas & 2 \\
\hline
\end{tabular}

O fato de os clientes terem reconhecido a empresa como parceira de negócios, consolidando a missão dele, foi um dos pontos altos na pesquisa. Isso confirma a afirmação de Anton (1996), que considera a percepção, por meio da experiência ao longo do tempo, como resultado do foco no cliente. 
O investimento da empresa na implantação de um sistema de CRM demonstra seu movimento na direção de aumentar sua eficiência para sustentar sua participação de mercado e sua posição competitiva. Tal estratégia busca, também, a satisfação do cliente e, segundo Gonçalves (2000), os resultados concorrem para uma melhora do processo. Nesse sentido, a pesquisa mostrou que houve evidências de melhorias no processo organizacional que envolve diversas áreas da empresa e uma centralização das informações. Tal reflexo pode ser visto como efeito necessário ao bom uso do CRM.

Com relação à satisfação do cliente, ficou evidente, tanto pela percepção dos gerentes, quanto pelas respostas diretas dos clientes, que ela é uma realidade no relacionamento entre o cliente e a empresa. Foram ressaltados como evidências desta satisfação: a qualidade dos produtos e serviços, a qualidade do atendimento e o relacionamento pessoal do gerente, conforme Tabela 5. Há, portanto, espaço para uma ação gerencial na melhoria do relacionamento pessoal. Aqui se busca, também, identificar novas oportunidades de negócio com o objetivo de conquistar a fidelidade do cliente em consonância com a literatura (Simões, 2002).

Tabela 5: Percepção dos Motivos da Satisfação do Cliente

\begin{tabular}{c|c|c}
\hline \hline $\begin{array}{c}\text { Satisfação Cliente } \\
\text { Percepção de Motivos }\end{array}$ & Sim & Não \\
\hline Atendimento e serviços & 6 & 0 \\
\hline Satisfação do cliente & 5 & 1 \\
\hline Qualidade dos produtos & 3 & 2 \\
\hline Relacionamento pessoal & 3 & 1 \\
\hline \hline
\end{tabular}

Vale observar que o contato pessoal do gerente foi evidenciado como importante, sendo complementado pelos outros tipos de canais de relacionamento disponibilizados pela empresa, apresentados no Gráfico 1. A estratégia de utilização do CRM pode reforçar ou não a importância deste canal; portanto deve-se considerar com relevância a relação humana, conforme se aborda na literatura.

\section{Gráfico 1: Canais de Relacionamento com o Cliente}

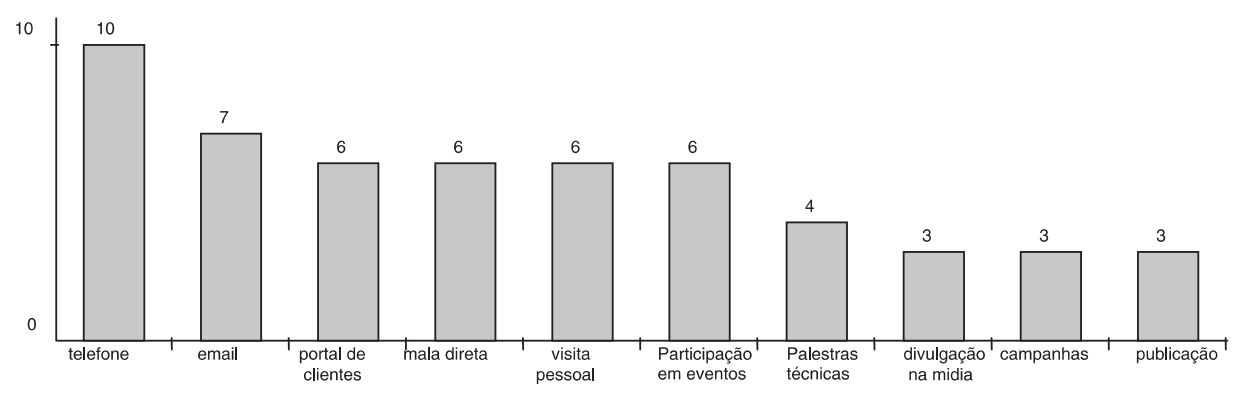


A integração do cliente com a empresa foi reconhecida por meio da identificação de vários canais de comunicação, oferecidos como alternativas de procedimentos para o relacionamento com a empresa. Tais procedimentos são mencionados como forma de proporcionar um valor superior ao cliente e tem como desafio construir e manter relacionamentos estáveis e duradouros com os clientes. Nesses relacionamentos, surge a internet, em diversas feições, como ponto forte de integração e comunicação em adesão a diversos autores.

\section{Pergunta Síntese e Análise de Correspondências}

Foram identificados vários papéis para o gerente no processo de utilização do CRM conforme mostra o Gráfico 2. Tais papéis vão desde o contato do gerente até a sua atuação como agente de mudança e na melhoria dos negócios da empresa.

\section{Gráfico 2: Papel Reservado ao Gerente no Uso de Tecnologia CRM}

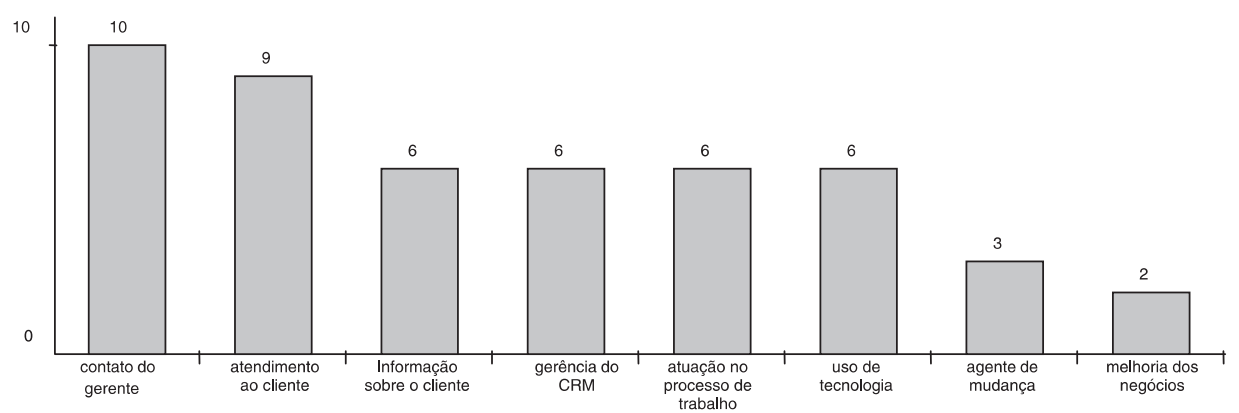

Pode-se também perceber a correspondência da atuação do gerente com os processos organizacionais, apresentada no Gráfico 3. Os objetivos da empresa são evidenciados pela atuação do gerente no processo de trabalho e na melhoria dos negócios. A melhoria do relacionamento com o cliente está ligada à gerência das ações de atendimento por meio do uso da tecnologia. $\mathrm{O}$ processo de apoio às atividades gerenciais se evidencia mais fortemente pelo contato do gerente e também pelo seu papel como agente de mudança e mantenedor das informações.

$\mathrm{Na}$ triangulação das informações, os gerentes executivos confirmaram muitos dos papéis atribuídos aos gerentes. Os gerentes regionais enfatizaram a relevância do gerenciamento das informações e da sua utilidade no atendimento ao cliente e nos seus contatos. É, portanto, um papel estratégico na condução da melhoria dos negócios e na sua atuação junto a outros funcionários da empresa. Também os clientes consideraram que o gerente desempenha papel imprescindível e fundamental de intermediação entre o cliente e a empresa, buscando conhecer tudo o que se passa com o cliente. 


\section{Gráfico 3: Correspondência entre o Papel do Gerente e os Processos Organizacionais}

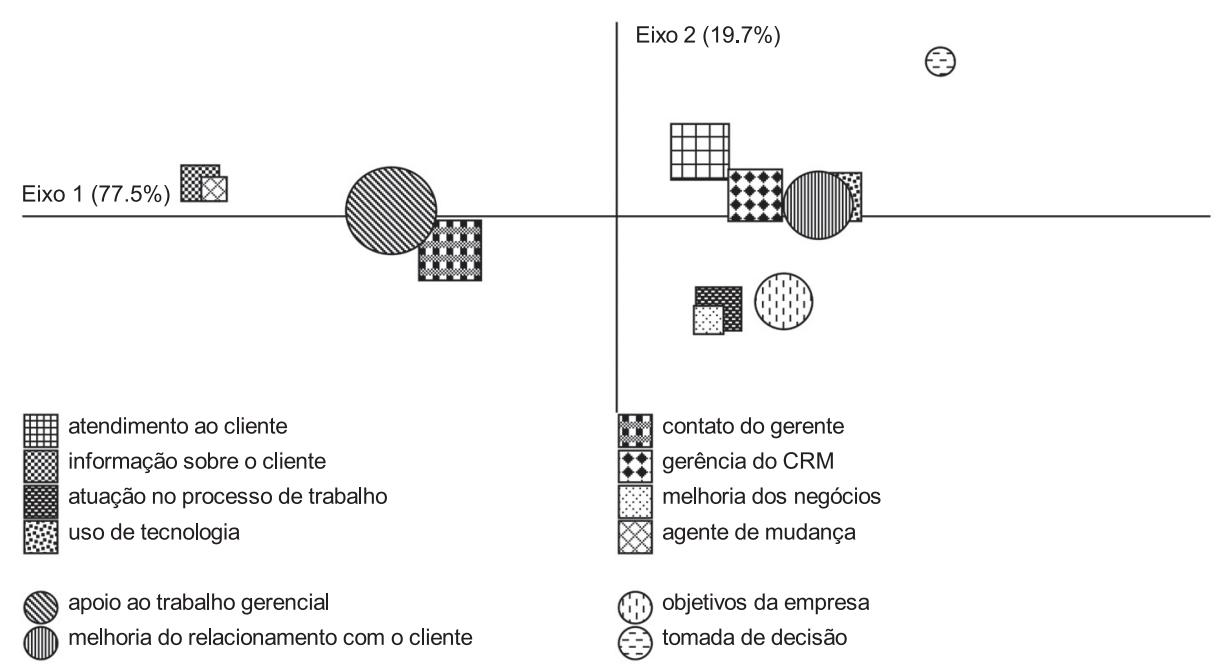

\section{Conclusão}

Em face dos resultados obtidos e da síntese da análise realizada, pode-se perceber que o gerente passa a ter uma postura mais proativa em relação ao contato e ao atendimento do cliente, uma vez que as informações decorrentes da utilização do CRM possibilitam gerenciamento mais efetivo do processo de trabalho e melhor planejamento das atividades.

Entretanto ficou claro que tais mudanças estão acontecendo em função de uma modificação nos processos de trabalho de toda a empresa, a qual exige a documentação de todos os contatos com o cliente para a obtenção de um registro histórico, com o objetivo de facilitar a interação do cliente com a empresa. O gerente, por deter boa parte das informações, é o principal ator nesse processo de mudança. Tapscott e Caston (1995) afirmam que o desafio do atual ambiente empresarial competitivo é a mudança no enfoque gerencial.

O uso da tecnologia CRM abre oportunidade, então, para que o gerente possa antecipar-se às necessidades e acompanhar as solicitações dos clientes. Neste sentido, os resultados mostraram que os clientes têm percebido melhoria contínua no relacionamento e nos contatos, por meio dos diversos canais de comunicação.

Além da melhoria do relacionamento, proposta por um sistema de gerência de relações com o cliente, pode-se perceber também uma melhoria nos negócios, 
em função do controle de contas e da condução de ações, numa atuação estratégica do gerente. Tal atuação não era possível antes da utilização do CRM, por não haver possibilidade de obter informações de todos os departamentos relevantes no processo analítico. Foi visto que, na prática, o CRM tem mecanismos para superar esta dificuldade.

Também na empresa como um todo foram identificadas vantagens com a utilização do CRM via consolidação e centralização das informações, que possibilitaram facilidades administrativas e agilidade na comunicação interna, viabilizando uma abordagem única ao cliente. As constatações obtidas para a empresa estudada podem ser admitidas como vantagem competitiva.

Em resumo, pode-se verificar, no presente estudo, que houve mudança na postura dos gerentes regionais da empresa pesquisada, possibilitada pela implantação e utilização de um sistema de gerenciamento do relacionamento com o cliente (CRM). Os resultados mostram que os gerentes fazem uso das informações para aperfeiçoar o processo do serviço, reduzir os níveis dos problemas e fortalecer o negócio, conforme Anton (1996).

Os pontos principais dessa nova postura baseiam-se nos novos processos organizacionais, na satisfação dos gerentes como usuários do sistema que possibilita maior controle gerencial, na busca do foco no cliente, na satisfação do cliente em relação ao contato e atendimento e no papel do gerente como agente de mudança.

Sabe-se, entretanto, que qualquer método ou técnica empregados em uma pesquisa possuem restrições. Assim, o presente estudo de natureza qualitativa e caráter exploratório também possui limitações inerentes às escolhas feitas para realizá-lo, tais como: a subjetividade das análises, a percepção do pesquisador, o limite do foco e a escolha do caso. O próprio tema abordado, CRM, é pouco disseminado, o que dificulta comparações com outros estudos.

Para aumentar o conhecimento sobre o assunto, sugere-se fixar o CRM, não apenas como um repositório de dados vindos de diversas áreas da empresa e com elas interligados; mas como um sistema de informação (SI) com suas características e vantagens, testar o CRM sob a ótica dos clientes, explorar fundamentos teóricos do CRM, verificando se há predominância do marketing ou da tecnologia da informação (TI), criar tipologias de relacionamento baseadas em CRM e mudanças. Fica também a sugestão para o refinamento das análises aqui suscitadas e o desenvolvimento de outros estudos com hipóteses elaboradas a partir dos resultados obtidos, ou a própria replicação deste estudo, em comparações com outras organizações e gerentes.

Artigo recebido em 29.01.2004. Aprovado em 06.08.2004. 


\section{ReferênCias Bibliográficas}

Anton, J. (1996).

Customer relationship management: making hard decisions with soft numbers. New Jersey: Prentice Hall.

Applegate, L. M.,

Holsapple, C. W.,

Kalakota, R.,

Radermacher, F. J. \&

Whinston, B. A. (1996).

Eletronic commerce: building blocks of new business oportunity. Journal of Organizational Computing and Electronic Commerce, 6(1), 1-10.

Bardin, L. (1977). Análise de conteúdo. Lisboa: Edições 70.

Bateman, T. S., \&

Crant, J. M. (1993).

The proactive component of organizational behavior: a measure and correlates. Journal of Organizational Behaviour, 14, pp. 103-118.

Bretzke, M. (2000).

Marketing de relacionamento e competição em tempo real. São Paulo: Atlas.

Brynjolfsson, E., \&

Hitt, L. (1993, April).

Paradox lost? Firm-level evidence on the returns to information system spending. Management Science, 42(4), 541-558.

Carey, C. C. (1989, March/April).

Customers become customers... again! The direct marketing opportunity. Directions, 11(2), 2.
Casotti, L. (1995, setembro).

O desafio de pensar e ensinar marketing. RBAC-Revista Brasileira de Administração Contemporânea, 1(5), 6-21.

Chein, L., \&

Cabrera, M. (2000).

Com a palavra, o consumidor. Recuperado em 9 novembro, 2000, de http://intermanagers.com.br/ hsmp notes.detail

Churchill, G. (1999).

Marketing research (7a ed.). Orlando: The Dryden Press.

Davis, J., \&

Joyner, E. (2000).

Successful customer relationship management. SAS e-intelligence: the power to know, pp. 1-7. Texto fornecido na disciplina Marketing e Tecnologia de Negócios do Programa de Pós-graduação em Administração (PROPAD), UFPE.

Dornelas, J. S. (2002).

Sistemas de informações executivas. In: T. A. Almeida, \& F. S. Ramos (Orgs.). Gestão da informação: na competitividade das organizações (p.310). Recife: Ed. Universitária da UFPE.

Dwyer, F.,

Schurr, P. H., \&

Oh, S. (1987, April).

Developing buyer-seller relationships. Journal of Marketing, 51, pp.11-27. 
Godoy, A.S. (1995, março/abril).

Introdução à pesquisa qualitativa $\mathrm{e}$ suas possibilidades. RAE - Revista de Administração de Empresas, 35(2), 57-63.

Gonçalves, J. E. L. (2000, janeiro/março). As empresas são grandes coleções de processos. RAE - Revista de Administração de Empresas, 40(1), 57-63.

Hair, J. F.,

Anderson, R. E.,

Tatham, R. I. \&

Black, W. C. (1994).

Multivariate data analysis (3rd ed.).

New Jersey: Prentice-Hall.

Homburg, C.,

Workman, J. P., Jr., \&

Jensen, O. (2000, Fall).

Fundamental changes in marketing organization: the movement toward a customer-focused organizational structure. Journal of Academy of Marketing Science, 28(4), 459-478.

Krippendorff, K. (1980).

Content analysis: an introduction to its methodology. Beverly Hills, CA: Sage Publications.

Laville, C., \&

Dionne, J. (1999).

A construção do saber: manual de metodologia da pesquisa em ciências humanas. Porto Alegre: UFMG.

Lopes, A. (2001).

CRM em um cenário de mudanças. In: L. C., Zenone (Org.). Customer relationship management (CRM) conceitos e estratégias: mudando a estratégia sem comprometer o negócio (p. 156) São Paulo: Atlas.
Maçada, A. C. G., \&

Borenstein, D. (2000).

Medindo a satisfação dos usuários de um sistema de apoio à decisão. Anais do Encontro Nacional dos Programas de Pós-Graduação em Administração, Rio de Janeiro, RJ, 24.

Machado-da-Silva, C. L.,

Fonseca, V. S., \&

Fernandes, B. H. R. (1999).

Mudança e estratégia nas organizações: perspectivas cognitiva e institucional. In: M. M. F. Vieira, \& L. M. B. Oliveira (Orgs.). Administração Contemporânea Perspectivas Estratégicas. São Paulo: Atlas.

Manzione, S., Jr. (2001).

Fator humano no CRM alavancagem do sucesso. In: L. C. Zenone (Org.). Customer relationship management (CRM) conceitos e estratégias: mudando a estratégia sem comprometer o negócio. São Paulo: Atlas.

Marconi, M. A., \&

Lakatos, E. M. (1990).

Técnicas de pesquisa. (2a ed.). São Paulo: Atlas.

Marshall, C., \&

Rossman, G. B. (1994).

Designing qualitative research. (2a ed.). Thousand Oaks, CA: Sage Publications.

Mckenna, R. (1998).

Competindo em tempo real: estratégias vencedoras para era do cliente nunca satisfeito. Rio de Janeiro: Campus. 
Meirelles, F. S. (1994).

Informática: novas aplicações com microcomputadores. (2a ed.). São Paulo: Makron Books / McGraw-Hill.

Miles, M., \&

Huberman, M. (1994).

Qualitative data analysis. Thousand Oaks, CA: Sage Publications.

Morton, M. S. S. (1991).

The corporation of the 1990s: information technology and organizational transformation. New York: Oxford University Press.

Petrini, M., \&

Pozzebon, M. (2000).

Interação usuário-sistema: um estudo empírico sobre a proatividade no uso de sistemas de informação. Anais do Encontro Nacional dos Programas de Pós-Graduação em Administração, Rio de Janeiro, RJ, 24.

Poser, D. V. (2001).

Relacionamento com os clientes externos, internos e estratégias de comunicação com o mercado. In: L.

C. Zenone (Org.). Customer relationship management (CRM) conceitos e estratégias: mudando a estratégia sem comprometer o negócio (p. 156). São Paulo: Atlas.

Rapp, S., \&

Collins, T. L. (1991).

Maximarketing. São Paulo: McGrawHill.

Shirley, R. (1976, novembro/dezembro).

Um modelo para análise da mudança organizacional. RAE - Revista de Administração de Empresas, 16(6), 37-43.
Simões, C. F. (2002).

Logística e comércio eletrônico. In: T. A. Almeida, \& F. S. Ramos (Orgs.). Gestão da informação: na competitividade das organizações (p.310). Recife: Ed. Universitária da UFPE.

Stake, R. (1994).

Case studies. In: N. K. Denzin \& Y. S. Lincoln. Handbook of qualitative research. Thousand Oaks, CA: Sage Publications.

Stone, P. J., \&

Kirsch, J. (1996).

The general inquirer: a computer approach to content analysis. Cambridge: MIT Press.

Swift, R. (2001).

CRM Customer relationship management: o revolucionário marketing de relacionamento com o cliente (p.493). Rio de Janeiro: Campus.

Tapscott, D., \&

Caston, A. (1995).

Mudança de Paradigma. São Paulo: Makron Books.

Torkzadeh, G., \&

Doll, W. J. (1999).

The development of a toll for measuring the perceived impact of information technology on work. Omega, 27, pp. 327-339.

Venkatraman, N. (1994, Winter).

IT-Enabled Business Transformation: from automation to business scope redefinition. Sloan Management Review, 35(2), 72-87. 
Weber, R. P. (1990).

Basic Content Analysis. (2nd. ed.). Newbury Park, CA: Sage Publications. (Quantitative Applications in the Social Sciences, v. 049).
Yin, R. K. (2001).

Estudo de caso: planejamento e métodos. (2a. ed.). Porto Alegre: Bookman. 